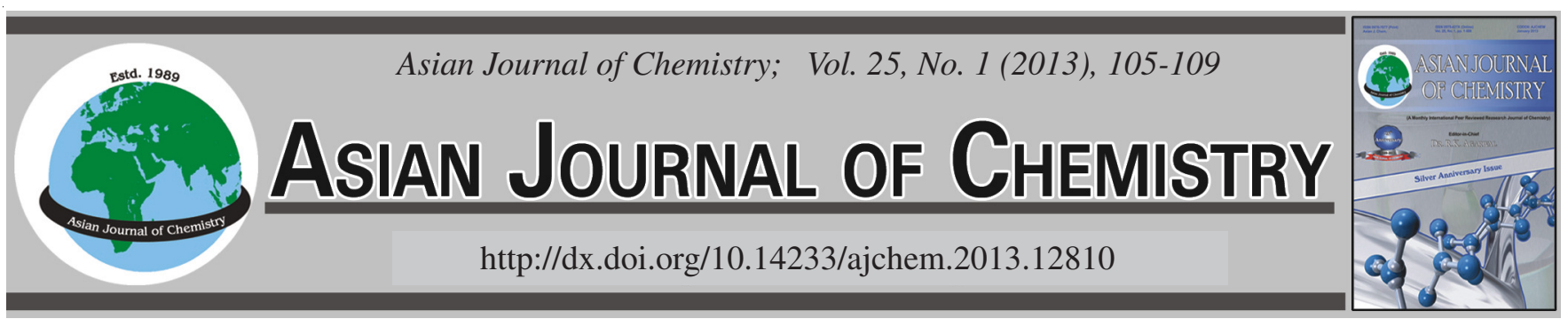

\title{
Leaching and Kinetic Modeling of Pyrite Cinder in Sulphuric Acid
}

\author{
Z.Z. SHI ${ }^{1,2, *}$, M.R. WANG ${ }^{2}$, G.K. ZHANG ${ }^{1}$ and L. ZHANG ${ }^{3}$
}

${ }^{1}$ School of Resources and Environmental Engineering, Wuhan University of Technology, Wuhan 430070, P.R. China

${ }^{2}$ College of Chemistry and Chemical Engineering, Kaifeng University, Kaifeng 475004, P.R. China

${ }^{3}$ College of Chemistry and Chemical Engineering, Henan University, Kaifeng, 475003, P.R. China

*Corresponding author: E-mail: zhzshi@163.com

(Received: 3 October 2011;

Accepted: 9 July 2012)

AJC-11829

\begin{abstract}
Pyrite cinder has often been utilized for the preparation of pigments, water purification materials and other materials including sponge iron powder, recovering iron, iron oxide red, ferrous sulfate and even bricks. In this work, orthogonal experiments were carried out to optimize the leaching conditions of pyrite cinder containing $48.94 \% \mathrm{Fe}, 13.9 \%$ acid insoluble substance, $0.64 \% \mathrm{Al}_{2} \mathrm{O}_{3}, 0.35 \% \mathrm{Cu}$, $1.3 \% \mathrm{~S}$ and $3.6 \% \mathrm{CaO}$ and then the corresponding kinetic equation was proposed. Effects of sulphuric acid concentration, excess coefficient, reaction temperature and reaction time on the leaching ratio were investigated. Statistical analysis indicates that the influence of the four factors on the leaching ratio is in the following sequence: reaction temperature, reaction time, excessive coefficient and sulphuric acid concentration. Furthermore, the optimized reaction conditions are obtained as reaction temperature $100{ }^{\circ} \mathrm{C}$, reaction time $3 \mathrm{~h}$, excessive coefficient 1.05 and sulphuric acid concentration $8 \mathrm{M}$. We also explored the reaction kinetics and the corresponding kinetic equation has been proposed. The reaction of pyrite cinder in sulphuric acid medium fits the surface chemical reaction model. The kinetics equation was obtained with apparent activation energy of $38.69 \mathrm{~kJ} / \mathrm{mol}$.
\end{abstract}

Key Words: Pyrite cinder, Sulphuric acid, Orthogonal experiment, Leaching kinetics.

\section{INTRODUCTION}

Pyrite cinder is the residual of the production of sulphuric acid from pyrite, which mainly contains iron oxide $\left(\mathrm{Fe}_{2} \mathrm{O}_{3}\right.$ and $\mathrm{Fe}_{3} \mathrm{O}_{4}$ ). A great deal of pyrite cinder has been produced in the world. For example, in China the average annual production of pyrite cinder is more than ten million tons. However, pyrite cinder has been rarely used directly as the raw materials for iron making because it contains only low grade iron oxide as well as sulfur and other impurities. The utilization of pyrite cinder generally involves the preparation of pigments and water purification materials. Recently, the preparation of sponge iron powder, recovering iron, iron oxide red, ferrous sulfate and bricks from pyrite cinder has been widely reported ${ }^{1-11}$.

It is important to investigate the reaction kinetics of leaching pyrite cinder. Previously some researchers have proposed some related kinetic equations. Yang et al. ${ }^{12}$ studied the reaction kinetics of calcine bearing high silicon in the $\mathrm{H}_{2} \mathrm{SO}_{4}-\mathrm{H}_{2} \mathrm{O}$ system. They suggested that the leaching ratio is consistent with the shrinking core model, which was expressed as $1+2(1-\mathrm{x})-3(1-\mathrm{x})^{2 / 3}=\mathrm{kt}$ with an apparent activation energy of $55.469 \mathrm{~kJ} / \mathrm{mol}$. Hou et al. ${ }^{13}$ explored the kinetics of acidolysis pyrite cinder and their results indicated that the acidolysis reaction is chemical reaction controlled with a kinetic equation of $1-\left(1-\mathrm{X}_{\mathrm{B}}\right)^{1 / 3}=\mathrm{kt}$ and an apparent activation energy of $51.755 \mathrm{~kJ} / \mathrm{mol}$. However, Zhan et al. ${ }^{14}$ insisted that the leaching kinetics of pyrite cinder is a diffusion controlling reaction with a kinetic equation of $1-\left(1-\mathrm{X}_{\mathrm{B}}\right)^{2 / 3}=\mathrm{kt}$ and an apparent activation energy of only $6.936 \mathrm{~kJ} / \mathrm{mol}$. It is clear that the reported results are inconsistent.

Herein, orthogonal experiments were performed to optimize the leaching conditions of pyrite cinder. And then a kinetic equation was proposed.

\section{EXPERIMENTAL}

Sulphuric acid (AR, $98 \%$ ), hydrochloric acid (AR, $36.5 \%$ ), stannous chloride (AR), methyl orange (AR) and diphenylamine sulphuric acid sodium salt (AR) was purchased from Sinopharm Chemical Reagent Co. Ltd. (China). Phosphorus mixture was prepared by dumping $150 \mathrm{~mL}$ of concentrated sulphuric acid into $700 \mathrm{~mL}$ of deionized water and then mixing with $150 \mathrm{~mL}$ of phosphoric acid after cooling. Pyrite cinder was supplied by Anhui Tongling Chemical Industry Co. with mass fractions of $48.94 \% \mathrm{Fe}, 13.9 \%$ acid insoluble substance, $0.64 \% \mathrm{Al}_{2} \mathrm{O}_{3}, 0.35 \% \mathrm{Cu}, 1.3 \% \mathrm{~S}$ and $3.6 \% \mathrm{CaO}$. Size distribution of the provided pyrite cinder is shown in Table-1. 


\begin{tabular}{lccccc}
\hline \multicolumn{7}{c}{ TABLE-1 } \\
SIZE DISTRIBUTION OF PYRITE CINDER \\
\hline \multirow{2}{*}{ Size (mm) } & $>0.300$ & $0.300-$ & $0.200-$ & $0.125-$ & \multirow{2}{*}{0.075} \\
\hline Faction (wt \%) & 2.66 & 14.80 & 20.90 & 58.19 & 3.45 \\
Fe (\%) & - & 44.23 & 47.98 & 49.35 & - \\
\hline
\end{tabular}

Treatment of pyrite cinder: To reuse the pyrite cinder, $30 \mathrm{~g}$ of pyrite cinder was added into a $250 \mathrm{~mL}$ three-necked bottle followed by the addition of sulphuric acid. The reaction was allowed at designed temperature under a stirring speed of $400 \mathrm{rpm}$. Then the reactants were collected by filtration and washing with deionized water for three times. The residues were dried for $2 \mathrm{~h}$ at $110 \pm 2{ }^{\circ} \mathrm{C}$ and then weighted (mg). The weight fraction of iron was determined and the leaching ratio was calculated according to the following equation:

$$
\text { Leaching rate }(\%)=\frac{\mathrm{m} \times \mathrm{Fe} \%-\mathrm{M} \times \mathrm{Fe}^{\prime} \%}{\mathrm{~m} \times \mathrm{Fe} \%} \times 100
$$

where, $\mathrm{m}$ is the weight of feed pyrite cinder ( $\mathrm{g}) ; \mathrm{Fe} \%$ is the weight fraction of iron in pyrite cinder; $M$ is the weight of residual solid after reacting with sulphuric acid (g); $\mathrm{Fe}^{\prime} \%$ is the weight fraction of iron in the residual solid.

Determination of the weight fraction of iron: Pyrite cinder $(1 \mathrm{~g})$ was accurately weighted and placed in a $250 \mathrm{~mL}$ beaker followed by $20 \mathrm{~mL}$ of concentrated hydrochloric acid. The pyrite cinder was heated to boiling and kept for $1 \mathrm{~min}$. The solution was transferred to a $250 \mathrm{~mL}$ volumetric flask after cooling to ambient. Then $25 \mathrm{~mL}$ of the prepared solution was transferred into a $250 \mathrm{~mL}$ conical flask followed by the addition of $8 \mathrm{~mL}$ of concentrated hydrochloric acid. Afterward, the solution was also heated to boiling and 6 drops of methyl orange was added. Then stannous chloride was slowly added dropwise. During this process, the conical flask was shaken severely. When redness of the solution exactly fades, the conical flask was cooled rapidly. After that, $50 \mathrm{~mL}$ of deionized water and $20 \mathrm{~mL}$ of phosphorus mixture were added. At the end, the mixture was titrated by $0.05 \mathrm{M} \mathrm{K}_{2} \mathrm{Cr}_{2} \mathrm{O}_{7}$ to stable fuchsia as terminal point using diphenylamine sulfonic acid sodium salt as the indicator.

\section{RESULTS AND DISCUSSION}

Leaching of pyrite cinder in sulphuric acid is a reaction at liquid/solid interface. The main influencing factors include ratio of liquid to solid, stirring speed, sulphuric acid concentration, excess coefficient, reaction temperature and reaction time. Zhan and Zheng ${ }^{14}$ systematically investigated the effects of stirring speed and the ratio of liquid to solid, showing the optimized stirring speed is $400 \mathrm{rpm}$. In previous work, it was proposed that the ratio of liquid to solid has little influence on the reaction when it is less than $4.7^{12}$. In the present work, we focused on the effects of sulphuric acid concentration, excess coefficient, reaction temperature and reaction time. An orthogonal array with four factors in four levels was employed to evaluate each factor and the results are summarized in Table- 2 .

According to the statistical analysis, the range results indicate that the influence of the four factors on the leaching ratio is in the following sequence: reaction temperature (0.212), reaction time $(0.0755)$, excessive coefficient $(0.0625)$ and sulphuric acid concentration (0.0577). It could be seen that reaction temperature is the most significant factor affecting the leaching ratio whereas other factors show similar effects. Therefore, the optimized reaction conditions are: reaction temperature is $100{ }^{\circ} \mathrm{C}$, reaction time is $3 \mathrm{~h}$, excessive coefficient is 1.05 and sulphuric acid concentration is $8 \mathrm{M}$. In practice, it is difficult to control the temperature at $100^{\circ} \mathrm{C}$ and hence reacting under pressure may be preferable.

TABLE-2

EFFECTS OF EXCESS COEFFICIENT (E), SULFURIC ACID CONCENTRATION (C, M), REACTION TEMPERATURE $\left(\mathrm{T},{ }^{\circ} \mathrm{C}\right)$ AND REACTION TIME $(\mathrm{t}, \mathrm{h})$ ON THE LEACHING RATIO (RL)

\begin{tabular}{cccccc}
\hline No. & $\mathrm{E}$ & $\mathrm{C} / \mathrm{M}$ & $\mathrm{T}\left({ }^{\circ} \mathrm{C}\right)$ & $\mathrm{t}(\mathrm{h})$ & $\mathrm{RL}$ \\
\hline 1 & 1.05 & 5.0 & 70 & 1.5 & 0.3925 \\
2 & 1.05 & 6.0 & 80 & 2.0 & 0.4442 \\
3 & 1.05 & 7.0 & 90 & 2.5 & 0.5615 \\
4 & 1.05 & 8.0 & 100 & 3.0 & 0.7334 \\
5 & 1.10 & 5.0 & 80 & 2.5 & 0.4732 \\
6 & 1.10 & 6.0 & 70 & 3.0 & 0.4440 \\
7 & 1.10 & 7.0 & 100 & 1.5 & 0.5326 \\
8 & 1.10 & 8.0 & 90 & 2.0 & 0.5737 \\
9 & 1.15 & 5.0 & 90 & 3.0 & 0.5476 \\
10 & 1.15 & 6.0 & 100 & 2.5 & 0.7265 \\
11 & 1.15 & 7.0 & 70 & 2.0 & 0.4771 \\
12 & 1.15 & 8.0 & 80 & 1.5 & 0.5103 \\
13 & 1.20 & 5.0 & 100 & 2.0 & 0.6349 \\
14 & 1.20 & 6.0 & 90 & 1.5 & 0.5239 \\
15 & 1.20 & 7.0 & 80 & 3.0 & 0.5481 \\
16 & 1.20 & 8.0 & 70 & 2.5 & 0.4616 \\
\hline $\mathrm{K} 1$ & 2.1316 & 2.0482 & 1.7797 & 1.9593 & \\
$\mathrm{~K} 2$ & 2.0235 & 2.1386 & 1.9758 & 2.1299 & \\
$\mathrm{~K} 3$ & 2.2615 & 2.1193 & 2.2067 & 2.2228 & \\
$\mathrm{~K} 4$ & 2.1685 & 2.2790 & 2.6274 & 2.2731 & \\
$\mathrm{k} 1$ & 0.5329 & 0.5121 & 0.4449 & 0.4898 & \\
$\mathrm{k} 2$ & 0.5059 & 0.5347 & 0.4940 & 0.5325 & \\
$\mathrm{k} 3$ & 0.5654 & 0.5298 & 0.5517 & 0.5557 & \\
$\mathrm{k} 4$ & 0.5421 & 0.5698 & 0.6569 & 0.5683 & \\
$\mathrm{R}$ & 0.0625 & 0.0577 & 0.2120 & 0.0755 & \\
\hline & & & & & \\
\hline
\end{tabular}

Fig. 1 shows the effects of reaction time on the leaching ratio. The reactions were conducted for different time of 1 , $1.5,2,2.5$ and $3 \mathrm{~h}$ under the condition of excess coefficient of 1.05 , sulphuric acid concentration of $6 \mathrm{M}$ and reaction temperature of $60^{\circ} \mathrm{C}$. Then the experiments were carried out at 70,80 and $90^{\circ} \mathrm{C}$. It could be seen from Fig. 1 that leaching ratio increases with reaction time at the initial stage and levels off after 150 min. Besides, the leaching ratio obviously increases with reaction temperature.

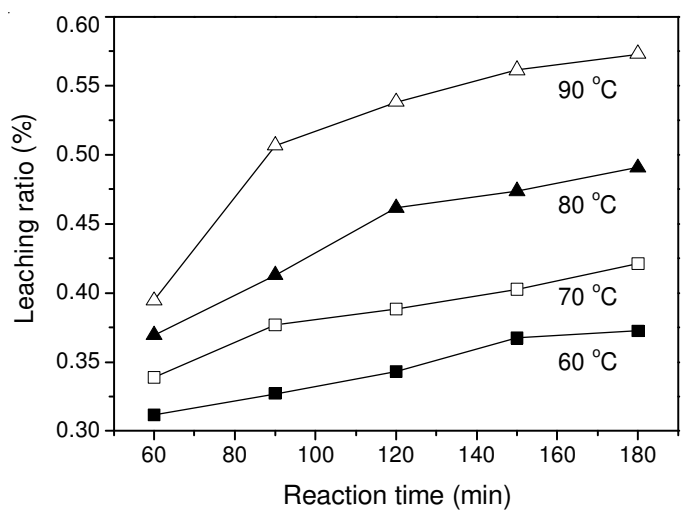

Fig. 1. Effects of reaction time on the leaching ratio at different reaction temperatures. (Origin 7.0) 
Effects of sulphuric acid concentration on the leaching ratio at different reaction temperatures are shown in Fig. 2. The experiments were operated with the condition of excess coefficient of 1.05 , reaction time of $2 \mathrm{~h}$. Results show that reaction ratio was enhanced with the concentration of sulphuric acid. However, considering the physical properties of the reaction slurry, the concentration of sulphuric acid should be avoided to be too high.

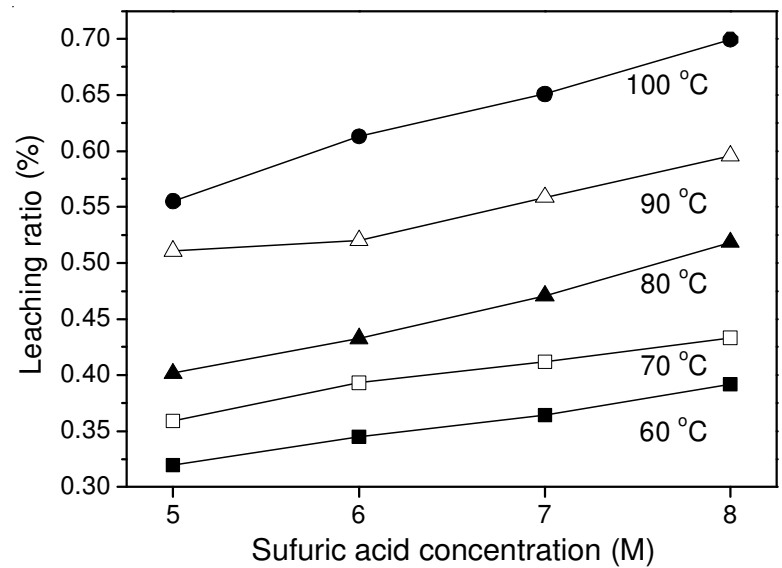

Fig. 2. Effects of sulfuric acid concentration on the leaching ratio at different reaction temperatures. (Origin 7.0)

Effects of reaction temperature on the leaching ratio were also investigated and the results are shown in Figs. 3 and 4. At the same concentration of sulphuric acid, the leaching ratios increase sharply with temperature, which are consistent with the results from orthogonal array experiments. It means that effects of reaction temperature on the leaching ratio are remarkable. The results shown in Fig. 4 have a similar tendency with those in Fig. 3.

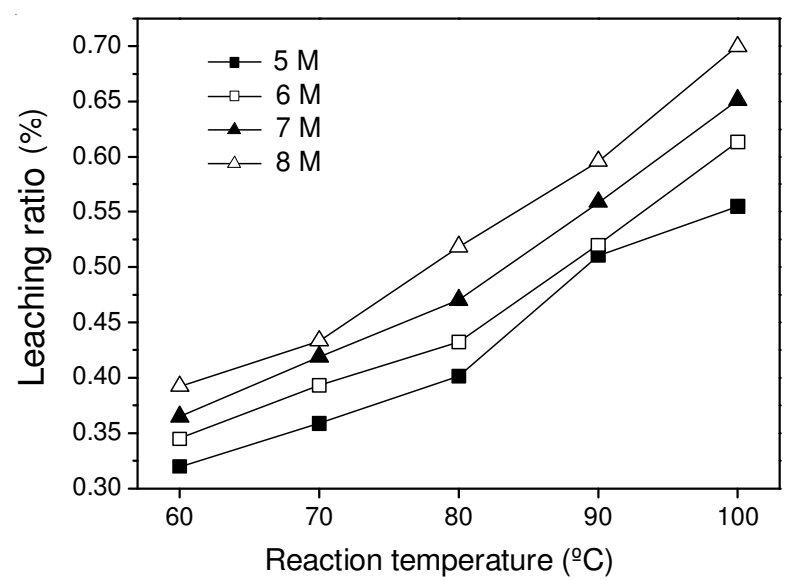

Fig. 3. Effects of reaction temperature on the leaching ratio under different sulfuric acid concentrations. (Origin 7.0)

Based on the above mentioned optimized reaction conditions, the reaction kinetics was explored. Pyrite cinder leaching in sulphuric acid medium is a reaction at liquid/solid interface without solid products. During the reaction, the size of pyrite cinder particles decreases continuously during the reaction process. The shrinking core model considers that the leaching process is controlled either by the diffusion of reactant through the solution boundary, or through a solid product layer, or by the surface chemical reaction rate. Assuming that

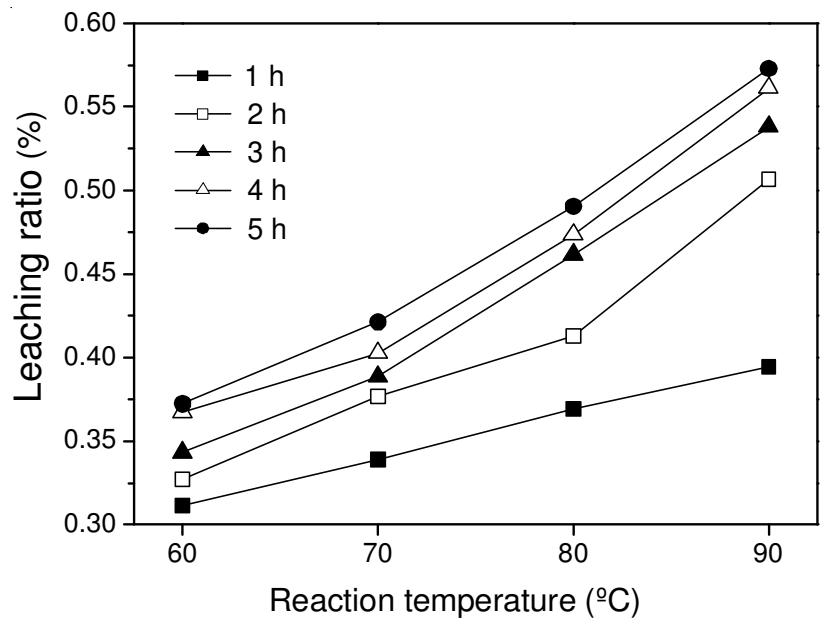

Fig. 4. Effects of reaction temperature on the leaching ratio at different reaction time. (Origin 7.0)

pyrite cinder particles have a spherical geometry and surface chemical reaction is the slowest step, the following expression of the shrinking core model can be used to describe the dissolution kinetics ${ }^{15}$ :

$$
1-\left(1-x_{B}\right)^{1 / 3}=k^{\prime} t
$$

Besides, there is not any gas reactant or products in this process. Similarly, when the diffusion between the solid phase and liquid phase is the rate controlling step, the following expression can be used $^{16}$ :

$$
1-\left(1-\mathrm{X}_{\mathrm{B}}\right)^{2 / 3}=\mathrm{k} \text { 't }
$$

Based on the analysis of the effects of reaction time on the leaching ratio, the above-mentioned two kinetics equations were fitted and the correlation coefficients (f) were summarized in Table-3. It could be found that the correlation coefficients of surface chemical reaction controlling kinetics eqn. (2) were slightly higher than those of kinetics eqn. (3), which indicates surface chemical reaction controlling kinetics model is more

\begin{tabular}{|c|c|c|c|c|c|c|c|}
\hline \multicolumn{8}{|c|}{$\begin{array}{c}\text { TABLE-3 } \\
\text { CORRELATION COEFFICIENTS }(f) \text { OF KINETIC MODEL } \\
\text { UNDER DIFFERENT REACTION CONDITIONS }\end{array}$} \\
\hline $\begin{array}{c}\mathrm{T} \\
\left({ }^{\circ} \mathrm{C}\right)\end{array}$ & $\begin{array}{c}\mathrm{t} \\
(\mathrm{min})\end{array}$ & $x_{\mathrm{B}}$ & $1-x_{\mathrm{B}}$ & $\begin{array}{l}1-(1- \\
\left.x_{\mathrm{B}}\right)^{1 / 3}\end{array}$ & $f$ & $\begin{array}{l}1-(1- \\
\left.x_{\mathrm{B}}\right)^{2 / 3}\end{array}$ & $f$ \\
\hline \multirow{5}{*}{60} & 60 & 0.3115 & 0.6885 & 0.1170 & \multirow{5}{*}{0.9875} & 0.2203 & \multirow{5}{*}{0.9870} \\
\hline & 90 & 0.3271 & 0.6729 & 0.1237 & & 0.2321 & \\
\hline & 120 & 0.3432 & 0.6568 & 0.1308 & & 0.2441 & \\
\hline & 150 & 0.3672 & 0.6328 & 0.1415 & & 0.2629 & \\
\hline & 180 & 0.3724 & 0.6276 & 0.1438 & & 0.2670 & \\
\hline \multirow{5}{*}{70} & 60 & 0.3505 & 0.6495 & 0.1340 & \multirow{5}{*}{0.9452} & 0.2500 & \multirow{5}{*}{0.9331} \\
\hline & 90 & 0.3768 & 0.6232 & 0.1458 & & 0.2704 & \\
\hline & 120 & 0.3885 & 0.6115 & 0.1512 & & 0.2796 & \\
\hline & 150 & 0.4026 & 0.5974 & 0.1578 & & 0.2907 & \\
\hline & 180 & 0.4213 & 0.5787 & 0.1667 & & 0.3056 & \\
\hline \multirow{5}{*}{80} & 60 & 0.3694 & 0.6306 & 0.1425 & \multirow{5}{*}{0.9690} & 0.2646 & \multirow{5}{*}{0.9673} \\
\hline & 90 & 0.4127 & 0.5873 & 0.1626 & & 0.2987 & \\
\hline & 120 & 0.4616 & 0.5384 & 0.1865 & & 0.3382 & \\
\hline & 150 & 0.4737 & 0.5263 & 0.1926 & & 0.3481 & \\
\hline & 180 & 0.4907 & 0.5093 & 0.2014 & & 0.3623 & \\
\hline \multirow{5}{*}{90} & 60 & 0.3944 & 0.6056 & 0.1540 & \multirow{5}{*}{0.9170} & 0.2842 & \multirow{5}{*}{0.9107} \\
\hline & 90 & 0.5067 & 0.4933 & 0.2099 & & 0.3757 & \\
\hline & 120 & 0.5381 & 0.4619 & 0.2270 & & 0.4025 & \\
\hline & 150 & 0.5613 & 0.4387 & 0.2402 & & 0.4226 & \\
\hline & 180 & 0.5723 & 0.4277 & 0.2466 & & 0.4323 & \\
\hline
\end{tabular}
appropriate. 
On the basis of eqn. (2), curves of $1-\left(1-\mathrm{X}_{\mathrm{B}}\right)^{1 / 3} v s$. reaction time was plotted in Fig. 5 and the slope is the reaction rate constant $\mathrm{k}^{\prime}$.

$$
\begin{gathered}
\mathrm{k}^{\prime}=\frac{\mathrm{kc}_{\mathrm{H}_{2} \mathrm{SO}_{4}}^{\mathrm{n}_{1}}}{\mathrm{R}_{\mathrm{s}}^{\mathrm{n}_{2}}} \\
\mathrm{k}=\mathrm{k}_{0} \exp \left(-\mathrm{Ea} / \mathrm{R}_{\mathrm{g}} \mathrm{T}\right)
\end{gathered}
$$

Equation (5) was substituted to eqn. (4):

$$
\ln \mathrm{k}^{\prime}=\ln \mathrm{k}_{0}-\frac{\mathrm{Ea}}{\mathrm{R}_{\mathrm{g}} \mathrm{T}}+\mathrm{n}_{1} \ln \mathrm{c}_{\mathrm{H}_{2} \mathrm{SO}_{4}}+\mathrm{n}_{2} \ln \frac{1}{\mathrm{Rs}}
$$

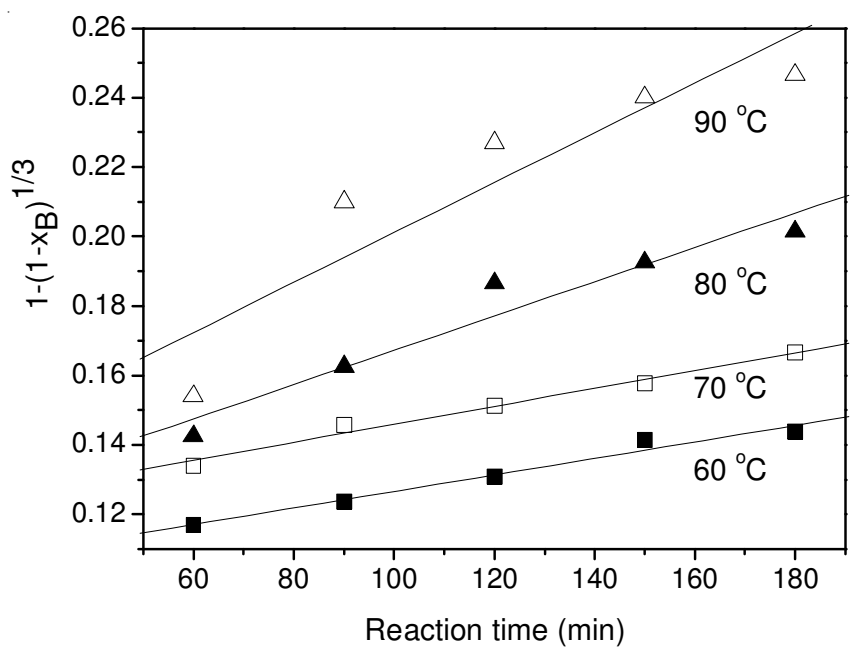

Fig. 5. Plots of $1-\left(1-\mathrm{X}_{\mathrm{B}}\right)^{1 / 3} v$ s. reaction time at different temperatures. (Origin 7.0)

Based on eqn. (6), curve of ln $\mathrm{k}^{\prime} v s .1 / \mathrm{T}$ was plotted in Fig. 6. The slope of the fitted line is $-\left(\mathrm{E}_{\mathrm{a}} / \mathrm{R}_{\mathrm{g}}\right)$, which equals to -4654 . Hence, the activation energy $E_{a}$ is calculated as 38.69 $\mathrm{kJ} / \mathrm{mol}$ and $\mathrm{k}_{0}=250$.

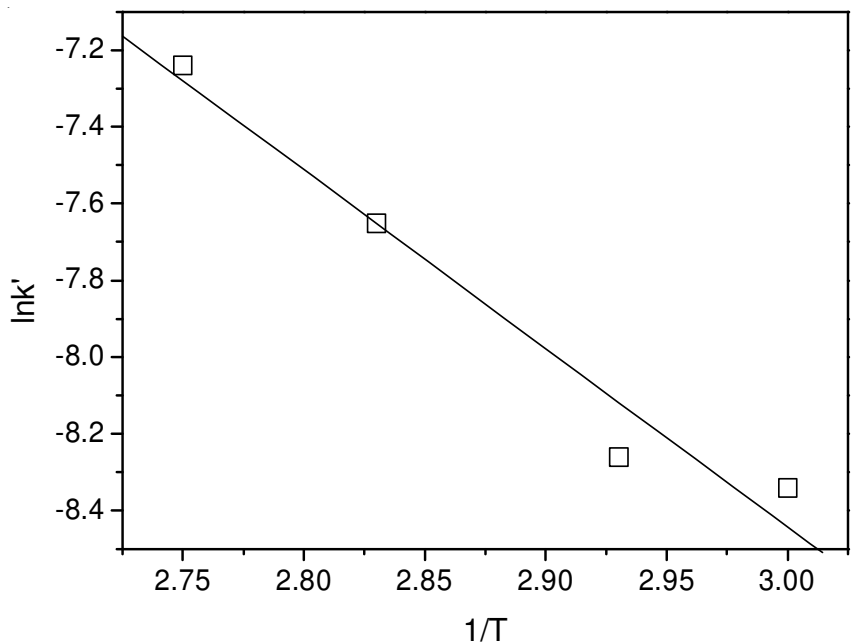

Fig. 6. Plot of $\ln \mathrm{k}^{\prime} v s .1 / \mathrm{T}$. (Origin 7.0)

Equation (6) was substituted to eqn. (2):

$$
\ln \left[1-\left(1-\mathrm{x}_{\mathrm{B}}\right)^{1 / 3}\right]=\ln \mathrm{k}_{0}-\frac{\mathrm{E}_{\mathrm{a}}}{\mathrm{R}_{\mathrm{g}} \mathrm{T}}+\mathrm{n}_{1} \ln \mathrm{c}_{\mathrm{H}_{2} \mathrm{SO}_{4}}+\mathrm{n}_{2} \ln \frac{1}{\mathrm{Rs}}+\ln \mathrm{t}
$$

Curves of $\ln \left[1-\left(1-\mathrm{X}_{\mathrm{B}}\right)^{1 / 3}\right]$ vs. $\ln \mathrm{C}_{\mathrm{H}_{2} \mathrm{SO}_{4}}$ were plotted in Fig. 7 in accordance with eqn. (7). It could be calculated that $n_{1}$ equals to $0.4947,0.4832,0.5376$ and 0.4500 at $60,70,80$ and $90{ }^{\circ} \mathrm{C}$, respectively and the average value is 0.4914 . Curves of $\ln \left[1-\left(1-\mathrm{X}_{\mathrm{B}}\right)^{1 / 3}\right]$ vs. $\ln \left[1 / \mathrm{R}_{\mathrm{s}}\right]$ were also plotted (Fig. 8) on the basis of eqn. (7). Accordingly, the following parameters were obtained: $\mathrm{n}_{2}$ equals to $0.1759,0.2035$ and 0.1250 at 70,80 and $90{ }^{\circ} \mathrm{C}$, respectively and the average value is 0.1681 .

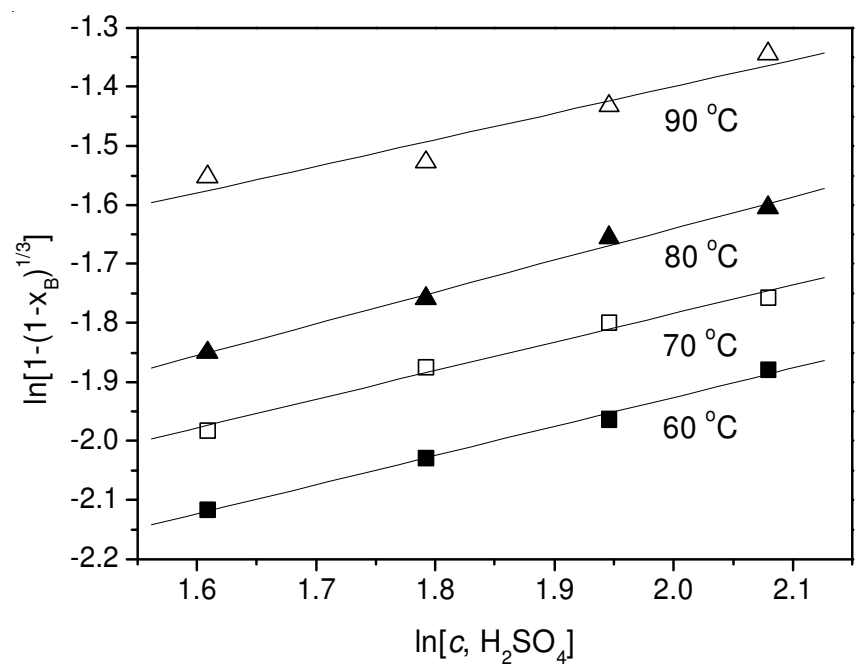

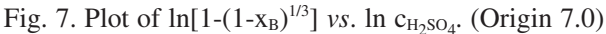

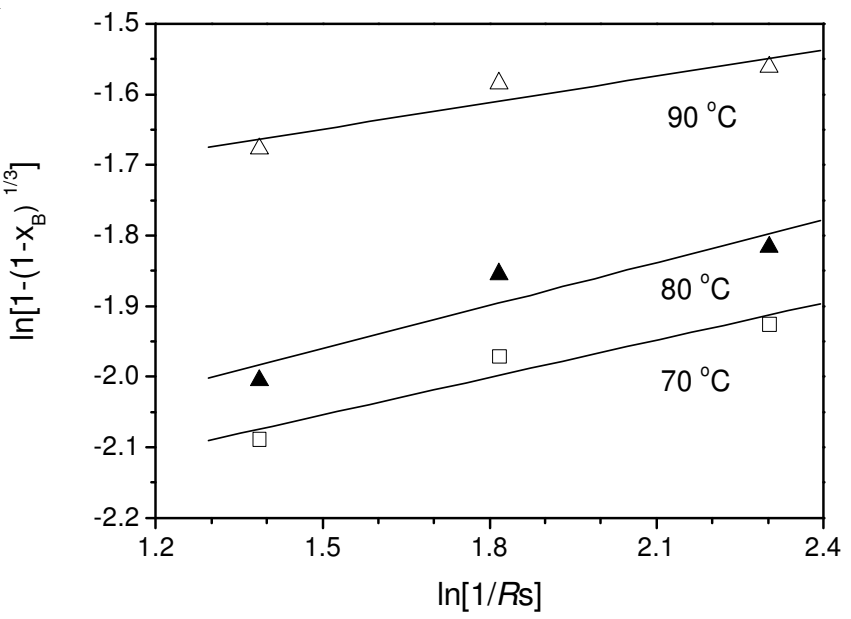

Fig. 8. Plot of $\ln \left[1-\left(1-\mathrm{x}_{\mathrm{B}}\right)^{1 / 3}\right]$ vs. $\ln \left[1 / \mathrm{R}_{\mathrm{s}}\right]$. (Origin 7.0$)$

The obtained parameters were substituted to eqn. (2) and the kinetics equation can be obtained as following:

$$
1-\left(1-\mathrm{x}_{\mathrm{B}}\right)^{1 / 3}=250 \times \exp \left(-\frac{38690}{\mathrm{R}_{\mathrm{g}} \mathrm{T}}\right) \times \mathrm{C}_{\mathrm{H}_{2} \mathrm{SO}_{4}}^{0.49} \times\left(\frac{1}{\mathrm{R}_{\mathrm{s}}}\right)^{0.17} \mathrm{t}
$$

Under the reaction temperature of $70{ }^{\circ} \mathrm{C}$ and sulphuric acid concentration of $6 \mathrm{M}$, the values of $\mathrm{x}_{\mathrm{B}}$ at different reaction time were calculated according to eqn. (8) and compared with the experimental results (Fig. 9) ${ }^{17}$. F test indicated that the model can be used to describe the reaction kinetic of pyrite cinder leaching in sulfuric acid.

\section{Conclusion}

(1) The orthogonal experiments have shown that reaction temperature is the most significant factor affecting the leaching ratio of pyrite cinder and the influence of sulphuric acid concentration, reaction time and excessive coefficient decreases in sequence. The optimized reaction conditions are as following: reaction temperature is $100{ }^{\circ} \mathrm{C}$, reaction time is $3 \mathrm{~h}$, excessive coefficient is 1.05 and sulphuric acid concentration is $8 \mathrm{M}$. 


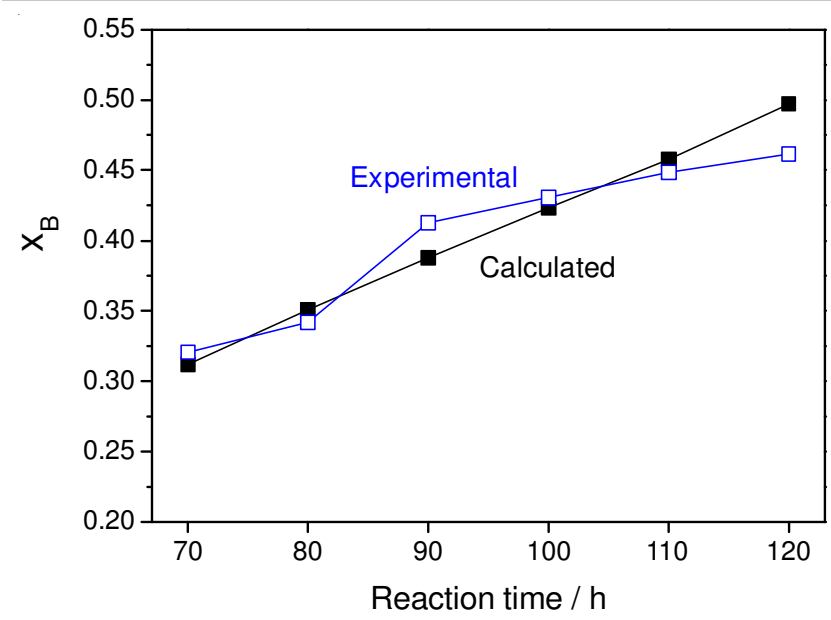

Fig. 9. Comparison of $\mathrm{x}_{\mathrm{B}}$ from calculation and experiments. (Origin 7.0)

(2) The reaction of pyrite cinder in sulphuric acid medium fits the surface chemical reaction model.

(3) The kinetics equation can be expressed as:

$$
1-\left(1-\mathrm{x}_{\mathrm{B}}\right)^{1 / 3}=250 \times \exp \left(-\frac{38690}{\mathrm{R}_{\mathrm{g}} \mathrm{T}}\right) \times \mathrm{C}_{\mathrm{H}_{2} \mathrm{SO}_{4}}^{0.49} \times\left(\frac{1}{\mathrm{R}_{\mathrm{S}}}\right)^{0.17} \mathrm{t}
$$

$\mathrm{F}$ test indicated that this equation can be used to describe the reaction kinetic of pyrite cinder leaching in sulfuric acid.

\section{ACKNOWLEDGEMENTS}

This work was supported by the Natural Science Foundation of Henan Educational Committee (No. 2008C530001).

\section{REFERENCES}

1. B.B. He, X.K. Tian, Y. Sun, C. Yang, Y.L. Zeng, Y.X. Wang, S.X. Zhang and Z.B. Pi, Hydrometallurgy, 104, 241 (2010).

2. L.Y. Sargsyan and A.M. Hovhannisyan, Russian J. Non-Ferrous Metals, 51, 386 (2010).

3. F. Mijangos, F. Varona, J.I. Lombrana and M. Diaz, Powder Technol., 115, 75 (2001).

4. Y.L. Chen and J.C. Chen, Resour. Envir. Eng., 20, 467 (2006).

5. Z.Q. Gong, S. Gong, B. Zhou and B.Z. Chen, Mining Metall. Eng., 26, 45 (2006).

6. A.V. Abdrakhimov, E.S. Abdrakhimova and V.Z. Abdrakhimov, Glass Ceram., 63, 130 (2006).

7. L.S. Rao, J.P. Barnwal, B. Govindarajan, S.D. Prasad and T.C. Rao, Trans. Ind. Inst. Metals, 48, 129 (1995).

8. D.Q. Zhu, D. Chen, J. Pan and H.Q. Li, J. Iron Steel Res. Int., 16, 345 (2009).

9. R. Ameta, J. Vardia, P.B. Punjabi and S.C. Ameta, Ind. J. Chem. Technol., 13, 114 (2006).

10. S. Chaliha and K.G. Bhattacharyya, Ind. J. Chem. Technol., 13, 499 (2006).

11. M. Gulfen and A.O. Aydin, Ind. J. Chem. Technol., 17, 145 (2010).

12. S.H. Yang, M.T. Tang, K. Zhang and Y. Meng, J. Cent. South Univ. Technol. (Nat. Sci.), 32, 583 (2001).

13. C.J. Hou and D.Q. Hou, J. Chongqing Univ. (Nat. Sci. Ed.), 21, 60 (1998).

14. S.X. Zhan and Y.J. Zheng, Chem. Eng., 34, 36 (2006).

15. C.F. Dickinson and G.R. Heal, Thermochim. Acta, 340, 89 (1999).

16. R. Dehghan, M. Noaparast and M. Kolahdoozan, Hydrometallurgy, 96, 275 (2009).

17. Z.Z. Shi, Chem. Eng. J., 37, 33 (2009) (In Chinese). 